\title{
AVALIAÇÃO DO POTENCIAL DE DESENVOLVIMENTO IN VITRO DE SEMENTES DE CALENDULA OFFICINALIS EM MEIO DE CULTURA MS
}

\section{Evaluation of in vitro development potential of calendula officinalis seeds in ms culture media}

https://doi.org/10.18593/eba.25134

Recebido em 11 de agosto de 2020 | Aceito em 2 de dezembro de 2020

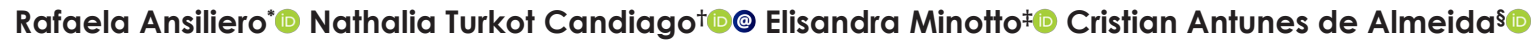 César Milton Baratto"(iD}

\footnotetext{
Graduanda em Biotecnologia Industrial pela Universidade do Oeste de Santa Catarina de Videira. Graduanda em Biotecnologia Industrial pela Universidade do Oeste de Santa Catarina de Videira.

‡ Pós-doutora em Ciência e Biotecnologia pela Universidade do Oeste de Santa Catarina; Doutora em Microbiologia Agrícola e do Ambiente pela Universidade Federal do Rio Grande do Sul; Mestre em Fitossanidade - Fitopatologia pela Universidade Federal de Pelotas

$\S$ Graduando em Biotecnologia Industrial pela Universidade do Oeste de Santa Catarina de Videira.

^ Pós-Doutor Empresarial pela Empresa Bioplus Desenvolvimento Biotecnológico Ltda; Doutor em Biologia Celular e Molecular pela Universidade Federal do Rio Grande do Sul; Mestre em Biologia Celular e Molecular pela Universidade Federal do Rio Grande do Sul; Coordenador do Curso de bacharelado em Biotecnologia Industrial; Professor e Pesquisador na Universidade do Oeste de Santa Catarina de Videira.
}

Resumo: Callendula officinalis é uma planta herbácea pertencente à família Asteraceae, a qual é capaz de apresentar atividades antioxidante e antibacteriana contra variados microrganismos. A técnica de micropropagação in vitro da espécie é alternativa para obter-se plantas com melhor qualidade e uniformidade, com produção de plantas sadias e com crescimento rápido. Com base nisso, este estudo busca avaliar o potencial de desenvolvimento in vitro, de sementes de Calendula officinalis, avaliando fatores como germinação, estabelecimento ecrescimento. As sementes utilizadas foram colhidas de plantas matrizes cultivadas em propriedade privada na cidade de IomerêSC/Brasil em março/2019, sendo transportadas até o laboratório da UNOESC. Após o preparo do meio de cultivo MS, as sementes foram lavadas, desinfestadas e posicionadas no meio de cultivo em tubos. Dez tubos continham corante artificial alimentício rosa e outros 10 não possuíam adição do corante, foram mantidas no escuro por 7 dias a $25^{\circ} \mathrm{C}$, decorrido tempo, transferidas para fotoperíodo de 16 horas. Após 36 dias, realizou-se a multiplicação in vitro em vidros com meio MS sem adição de corante e mantido nas mesmas condições. As sementes de calêndula apresentaram baixo desenvolvimento in vitro, sendo que as que desenvolveram são oriundas do meio de cultivo MS com adição do corante artificial alimentício rosa, atingido em 43 dias de cultivo uma média de $4 \mathrm{~cm}$ de comprimento. Apesar do corante artificial ter apresentado resultado positivo no desenvolvimento dos explantes, demais estudos são necessários para aprimorar técnicas mecânicas e químicas que auxiliem na germinação in vitro de sementes de calêndula.

Palavras-chave: Calêndula. Micropropagação. Corante alimentício. Germinação. 
Abstract: Calendula officinalis is a herbaceous plant belonging to the family Asteraceae, which is capable to present antioxidant and antibacterial activities against several microrganisms. The in vitro micropropagation technique of the species is na alternative to obtain a better quality, plant uniformity, as well as the production of healthy plants and rapid growth. Based on this, this study seeks to evaluate the potencial of in vitro development of Calendula officinalis seed's, evaluating factors such as germination, establishment and growth. The seeds used, were reaped from parent plants cultivated in a private property in the city of Iomerê-SC/Brasil in march/2019, and than transported to UNOESC laboratory. After the preparation of the culture media MS, the seeds were whased, disinfested and positioned in the culture media in tubes, where 10 tubes contained artificial food coloring and another 10 without addition of artificial food coloring, and kept ind the dark for 7 days at $25^{\circ} \mathrm{C}$, elapsed time, transferred for photoperiod of 16 hours. After 36 days, realized the in vitro multiplication in glasses with culture media MS without artificial food coloring and kept in the same conditions of photoperiod. The calendula seed's presented low in vitro development, being that, those that developed are from the culture media MS with addition of the artificial food color pink, reaching in 43 days of cultivation an average of $4 \mathrm{~cm}$ in length. Although artificial coloring presented a positive result in the development of explants, other studies are needed to improve the mechanical and chemical techniques that assist the in vitro germination of calendula seed's.

Keywords: Calendula. Micropropagation. Food coloring. Germination.

\section{INTRODUÇÃO}

A espécie Calendula officinalis L., popularmente conhecida como calêndula é uma planta herbácea anual da família Asteraceae, originária do mediterrâneo e cultivada em várias partes do mundo. ${ }^{1}$

A planta pode atingir até $60 \mathrm{~cm}$ de comprimento, com folhas alternas e inflorescência em capítulos longos e solitários, as flores são pequenas, amarelas e alaranjadas. ${ }^{2}$ Devido suas propriedades, o vegetal é utilizado para fins medicinais, ornamentais e em grande escala na culinária e na cosmetologia. ${ }^{3}$

Estudos constam que $C$. officinalis possui em sua composição diversos compostos químicos, vindo a apresentar atividade antioxidante e antibacteriana contra diversos microrganismos. ${ }^{4}$ Isso se deve segundo, ${ }^{2}$ pelo alto teor de óleos essenciais, carotenoides, flavonoides, saponinas, mucilagens, ácidos orgânicos, resinas e também minerais que a espécie apresenta.

A micropropagação in vitro de calêndula é uma técnica alternativa para a propagação desta espécie, garantindo maior qualidade e uniformidade, com produção de plantas sadias a uma velocidade maior do que em métodos convencionais. ${ }^{5}$ Além disso, a técnica possibilita a produção de mudas em larga escala, idênticas a planta matriz, o que auxilia na conservação da identidade genética, garantindo material genético de alto valor agregado. ${ }^{6}$

Desta forma, a micropropagação serefereao processo no qual tecidos, órgãos ou células podem ser cultivadas assepticamente em meio de cultura, sob condições controladas. ${ }^{7} \mathrm{O}$ meio de cultivo mais utilizado para este fim é o meio MS, o qual possui em sua composição sais minerais (macro e micronutrientes), carboidratos e vitaminas fundamentais para o desenvolvimento vegetal. ${ }^{8}$ Além disso, o meio pode ser suplementado com fitormônios, o que garante maior desenvolvimento vegetal. 9

Qualquer órgão ou tecido vegetal pode ser utilizado na técnica de micropropagação, com destaque para a utilização de sementes, ápices caulinares, segmentos nodais, gemas adventícias e cultura de raízes..$^{10}$ Assim, este sistema de cultivo depende do controle de inúmeras variáveis, como 
a densidade do fluxo de fótons, o fotoperíodo, a temperatura e fatores nutricionais como sais minerais, carboidratos e vitaminas. ${ }^{7}$

Várias etapas são necessárias para se obter êxito na micropropagação, além do estabelecimento são necessários subcultivos, devido ao esgotamento dos constituintes do meio de cultura e ao acúmulo de compostos tóxicos. ${ }^{6} \mathrm{De}$ outra forma, a presença de agentes contaminantes e a perda por oxidação, são fatores limitantes para a técnica. ${ }^{11}$

Tendo em vista a ampla gama de aplicações da espécie, e de sua importância econômica, este estudo propõe uma avaliação do potencial de desenvolvimento in vitro, de sementes de Calendula officinalis, avaliando fatores como germinação, estabelecimento e o crescimento in vitro.

\section{MATERIAL E MÉTODOS}

O presente trabalho foi desenvolvido no laboratório de Biotecnologia I e Biologia Vegetal no Núcleo Biotecnológico da Universidade do Oeste de Santa Catarina (UNOESC) em Videira, durante o componente curricular Cultivo de Células e Tecidos.

\subsection{SELEÇÃO DA PLANTA MATRIZ}

As sementes utilizadas no desenvolvimento do trabalho foram coletadas de plantas matrizes de Calendula officinalis, as quais foram cultivadas no município de Iomerê-SC/Brasil, em propriedade privada com latitude $27^{\circ}$ oo' $15^{\prime}$ 'S, longitude $51^{\circ} 14^{\prime}$ 32 "W e altitude 847 metros. As plantas possuíam idade aproximada de 98 dias, com média de $40 \mathrm{~cm}$ de altura e 4-5 botões florais em antese.
A colheita das sementes foi realizada em março/2019, de maneira manual aproximadamente 30 dias após a antese, quando as sementes exibiam coloração creme, marrom claro e variados tamanhos. As sementes foram armazenadas em recipiente seco e ao abrigo da luz, e após foram transportadas até a UNOESC.

\subsection{PREPARAÇÃO DO MEIO DE CULTIVO}

Para o cultivo das sementes, formulouse o meio MS de Murashige e Skoog, ${ }^{8}$ utilizando: $\mathrm{NH}_{4} \mathrm{NO}_{3} ; \quad \mathrm{KNO}_{3} ; \quad \mathrm{MgSO}_{4} 7 \mathrm{H}_{2} \mathrm{O} ; \quad \mathrm{MnSO}_{4} \mathrm{H}_{2} \mathrm{O}$; $\mathrm{ZnSO}_{4} 7 \mathrm{H}_{2} \mathrm{O} ; \mathrm{CuSO}_{4} \mathrm{H}_{2} \mathrm{O} ; \mathrm{CaCl}_{2} ; \mathrm{H}_{3} \mathrm{BO}_{3} ; \mathrm{KH}_{2} \mathrm{PO}_{4}$; $\mathrm{Kl} ; \mathrm{NaMoO}_{4} 2 \mathrm{H}_{2} \mathrm{O} ; \quad \mathrm{CoCL}_{2} 6 \mathrm{H}_{2} \mathrm{O} ; \quad \mathrm{Na}_{2}$ EDTA; $\mathrm{FeSO}_{4} 7 \mathrm{H}_{2} \mathrm{O}$; Âc. Nicotínico; Piridoxina; Tiamina; Glicina; Mio-inositol; Sacarose; Ágar; Corante artificial alimentício rosa; alterando o $\mathrm{pH}$ para 5,8.

\subsection{LAVAGEM E ESTABELECIMENTO DAS SEMENTES NO MEIO DE CULTIVO}

A lavagem das sementes de calêndula foi realizada utilizando detergente neutro e água corrente. Em câmara de fluxo laminar, as sementes foram imersas em Álcool 70\% sob agitação constante por 1 minuto para serem desinfestadas. Após, as sementes foram transferidas para hipoclorito de sódio 2,5\% com 2 gotas de detergente e deixadas sob agitação contínua por 10 minutos. Ao final, realizou-se a tríplice lavagem com água destilada estéril, a fim de eliminar qualquer resquício das soluções anteriores.

Em ambiente asséptico, realizou-se a inoculação e estabelecimento das sementes em 20 tubos de ensaio, 10 tubos continham meio de cultura acrescidos de corante artificial alimentício rosa, e outros 10 tubos não possuíam adição do corante. Com o auxílio de pinça estéril, as sementes foram posicionadas no meio de cultura, 
e posteriormente foram mantidas no escuro por 7 dias a temperatura ambiente de $25^{\circ} \mathrm{C}$. Decorrido tempo, as mesmas foram transferidas para sala de crescimento com fotoperíodo de 16 horas para iniciar sua adaptação. ${ }^{2}$

\subsection{MULTIPLICAÇÃO IN VITRO}

Após período de 36 dias mantidas em fotoperíodo, as plantas foram multiplicadas a fim de se obter novas cultivares. Em câmara de fluxo laminar, utilizando bisturi e pinça estéril, retirouse a planta do tubo de ensaio, posicionando-a horizontalmente em placa de Petri de vidro estéril para realização dos cortes. $\mathrm{O}$ corte foi realizado em maneira diagonal próximo as gemas laterais as quais iniciavam sua brotação e eliminando a raiz. O procedimento foi o mesmo para ambos os tubos, transferindo os explantes para vidros com meio MS sem adição de corante. Logo, os explantes foram mantidos em sala de crescimento nas mesmas condições anteriores.

\section{RESULTADOS}

As sementes de calêndula tiveram baixo percentual de germinação in vitro, apenas 10\% $(\mathrm{n}=2)$ vieram a germinar.

As sementes que vieram a germinar em média 12 dias após o estabelecimento, são oriundas do meio de cultivo MS com adição do corante artificial alimentício rosa. Durante o processo as sementes absorveram o corante, o que demostra que o mesmo foi eficaz na superação da dormência das sementes de calêndula (Figura 1).

A presença de agentes contaminantes, fungos e bactérias e a oxidação das sementes também foi observada.
As plantas tiveram satisfatório desenvolvimento in vitro, tendo atingido em 43 dias de cultivo uma média $4 \mathrm{~cm}$ de comprimento, sendo $1,5 \mathrm{~cm}$ referente a radícula, obtendo-se uma relação raiz/parte aérea de o,6 (Figura 1).

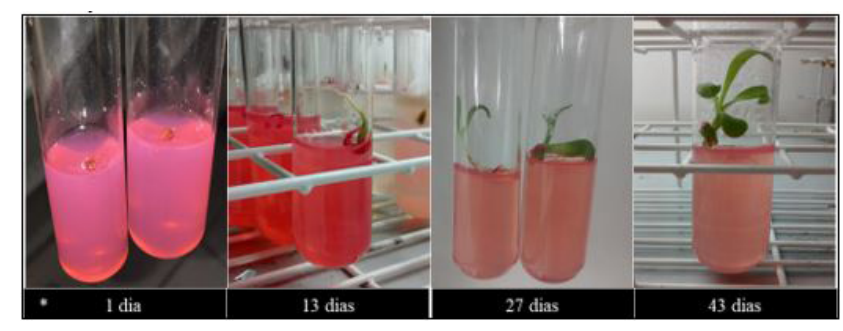

Figura 1 - Desenvolvimento, in vitro, de sementes de Calendula officinalis em meio de cultura MS com adição de corante artificial comestível rosa

Nota: *dias de desenvolvimento.

Desta forma, a partir de dois explantes foi possível obter, in vitro, três novas plântulas (Figura 2). As mesmas apresentaram desenvolvimento satisfatório e podem ser utilizadas posteriormente para obtenção de novas cultivares.

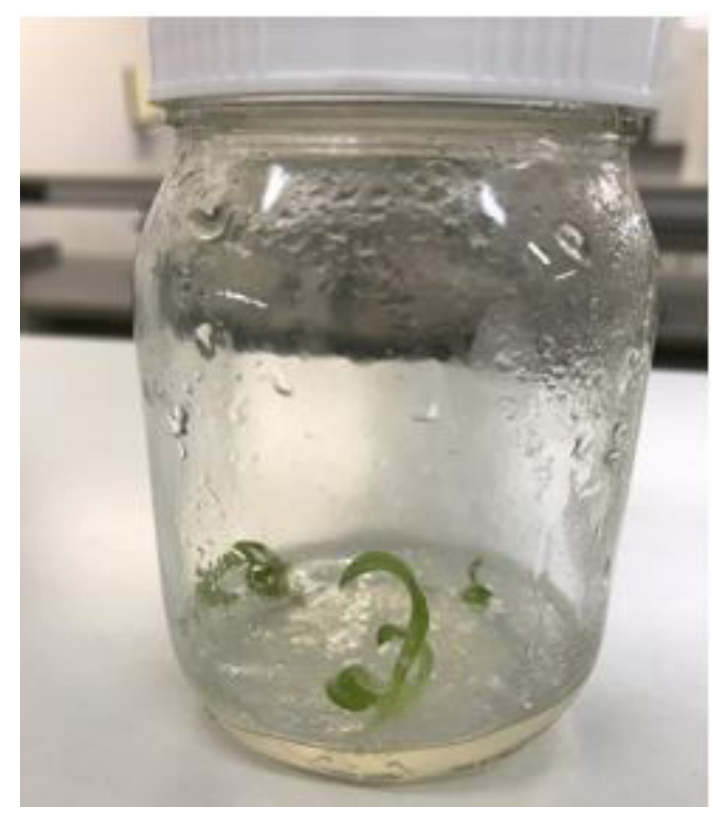

Figura 2 - Multiplicação de C. officinalis em meio de cultura MS. 


\section{DISCUSSÃO}

$\mathrm{O}$ resultado obtido por Belivacqua ${ }^{12}$ foi semelhante ao que se observou no presente trabalho, os quais constaram baixo potencial de germinação (10\%) de sementes de calêndula cultivadas, in vitro, em meio de cultura MS. Estudos afirmam que a remoção do tegumento contribui para a germinação de sementes do gênero e além disso, a imersão em solução de hipoclorito de sódio a $2,5 \%$ por 30 minutos auxilia no processo. ${ }^{5}$

Oatraso na germinaçãoéum fator limitante a produção em larga escala, tendo em vista que as plantas não responderão adequadamente aos estímulos do ambiente, ocorrendo atraso na floração e no desenvolvimento dos frutos. ${ }^{13}$ Tais fatores são empecilhos para o estabelecimento e para o desenvolvimento in vitro, sendo considerados aspectos limitantes para a técnica. ${ }^{11}$

A contaminação presente durante a realização da pesquisa é um problema sério não só no estabelecimento, como também na etapa de multiplicação das plantas. ${ }^{14}$ De maneira semelhante, Machado ${ }^{15}$ observou que $91 \%$ dos diásporosdeGochnatia polymorpha (less.) Cabrera, pertencente à família Asteraceae, possuíam contaminação fúngica quando mantidos por 30 dias em fotoperíodo de 16 horas. Logo, outros autores $^{14-16}$ também observaram alto índice de infestação de fungos ao realizar o estabelecimento in vitro, de sementes de atroveran e mandacaru, respectivamente.

A presença de contaminantes durante o estabelecimento se justifica pela presença de microrganismos que ocorrem de maneira natural, superficialmente ou nos tecidos internos das sementes. ${ }^{15}$ Quando os mesmos se encontram internamente as etapas de desinfecção e lavagem não são eficientes para eliminar tal infecção. ${ }^{15}$

De outra forma, Belivacqua ${ }^{12}$ constou que o comprimento médio das radículas das plântulas de calêndula foi de $3,48 \mathrm{~cm}$, obtendo relação raiz/ parte aérea de 1,40.

A multiplicação das plântulas foi fundamental devido ao esgotamento dos nutrientes no meio de cultura. ${ }^{6}$ A fim de otimizar o crescimento, pequenas quantidades de fitormônios podem ser utilizadas. ${ }^{9}$

\section{CONCLUSÃO}

É visto que o percentual de germinação in vitro de sementes de calêndula é baixo, além disso, o corante artificial comestível influencia significativamente na germinação, tendo em vista que as plântulas que vieram a germinar $10 \%(n=2)$ eram oriundas do meio de cultivo com presença do corante. Logo, mais estudos se fazem necessários a fim de desenvolver e aprimorar técnicas mecânicas e químicas que auxiliem na germinação in vitro, de sementes de calêndula. Além de aprofundar as análises dos compostos presentes em determinado corante, os quais desempenharam um positivo papel na germinação das mesmas.

Muitas técnicas vêm sendo aprimoradas para a superação de dormência em sementes da Família Asteraceae, ${ }^{13}$ ressalta o uso de tratamentos pré-germinativos, mecânicos, químicos e reguladores de crescimento para esse fim. 


\section{CONFLITO DE INTERESSE}

A pesquisa foi desenvolvida pelos acadêmicos durante o componente curricular Cultivo de Células e Tecidos, não havendo conflito de interesses.

\section{AGRADECIMENTOS}

\begin{abstract}
Nossos agradecimentos à professora Elisandra Minotto pelos ensinamentos e dedicação a nós repassados e a UNOESC pela oportunidade de podermos ampliar nossos conhecimentos e práticas através da pesquisa.
\end{abstract}

\section{REFERÊNCIAS}

1. Santos LMO, Oliveira LA, Tibulo EPS, Lima CP. Análise de amostras de flores de Calêndula (Calendula officinalis L., Asteraceae) comercializadas na grande Curitiba. J. Appl. Pharm. Sci. 2015; 36(2): 251-8.

2. Embrapa. Calêndula [Internet]. Corumbá: Embrapa Pantanal; 2006. [acesso em 2018 nov 11]. Disponível em: https://www.embrapa.br/busca-de-publicacoes/-/publicacao/812746/calendula

3. Grandi TSM. Tratado das plantas medicinais: mineiras, nativas e cultivadas. Belo Horizonte: Adequatio Estúdio; 2014.

4. Chaleshtori SH, Kachoie MA, Pirbalouti AG. Phytochemical analysis and antibacterial effects of Calendula officinalis essential oil. Biosci. Biotechnol. Res. Commun. 2016; 9(3): 517-22.

5. Bevilacqua CB, Reiniger LRS, Golle DP, Rosa FC. Desinfestação superficial, germinação e regeneração in vitro a partir de sementes de calêndula. Cienc Rural. 2011; 41(5). doi: http://dx.doi. org/10.1590/So103-84782011000500004

6. Nogueira JS, Costa FHS, Vale PAA, Luis ZG, Pereira JES. Micropropagação de bambu em largaescala: princípios, estratégias e desafios. Embrapa Recursos Genéticos e Biotecnologia; 2017.

7. Carvalho ACPP, Torres AC, Braga EJB, Lemos EEP, Souza FVD, Peters JA, et al. Glossário de cultura de tecidos de plantas. Plant Cell Culture \& Micropropagation. 2011. 7(1): 30-6o.

8. Murashige T, Skoog F. A revised medium for rapid growth and bio assays with tobacco tissue cultures. Physiologia plantarum. 1962; 15(3): 473-97.

9. Alexa IC, Pavăl P, Nicuţă D, Bran P, Patriciu OI, Grosu L, et al. Effects of hormones addition for in vitro plant development of calendulla officinalis. Scientific Study \& Research. Chemistry \& Chemical Engineering, Biotechnology, Food Industry. 2015; 16(1): 75-9. 
10. Guerra M, Nodari RO, Fraga HPF, Vieira LN, Fritsche Y. Biotecnologia I. 2016 [acesso em 2019 maio 16]. Disponível em: http://lfdgv.paginas.ufsc.br/files/2014/o8/Apostila-Biotec-2016.1-Final.pdf.

11. Oliveira HS, Lemos OF, Miranda VS, Moura HCP, Campelo MF, Santos LRR. Estabelecimento e multiplicação in vitro de brotos no processo de micropropagação de cultivares de bananeira (Musa spp.). Embrapa Amazônia Oriental. 2011; 41(9):369-76.

12. Bevilacqua CB. Germinação e cultivo in vitro de Calendula officinalis L [dissertação]. Santa Maria: Universidade Federal de Santa Maria; 2009.

13. Gonzaga APD. Germinação e micropropagação de Lychinophora pohlii Sch. Bip. (Asteraceae) [dissertação]. Diamantina: Universidade Federal dos Vales do Jequitinhonha e Mucuri; 2013.

14. Monfort, LEF, Pinto JEBP, Bertolucci SKV, Rossi ZTT, Lima AF, Silva ST, et al. Micropropagação e germinação de sementes in vitro de atroveran. Rev. Ceres. 2015; 62(2): 215-23.

15. Machado DFM. Estudo da germinação e do efeito de Trichoderma spp. No crescimento de Pochnatia polymorpha (Less.) Cabrera [dissertação]. Santa Maria: Universidade Federal de Santa Maria; 2012.

16. Martínez, MHP, Guimarães DT, Silva MMA, Ferreira LT. Desinfestação e germinação in vitro de sementes de mandacaru sem espinho. In: Anais do Congresso Nacional de Pesquisa e Ensino em Ciências, 2016. Campina Grande; 2016. 
